Volume 4 Number 2

JOURNAL OF
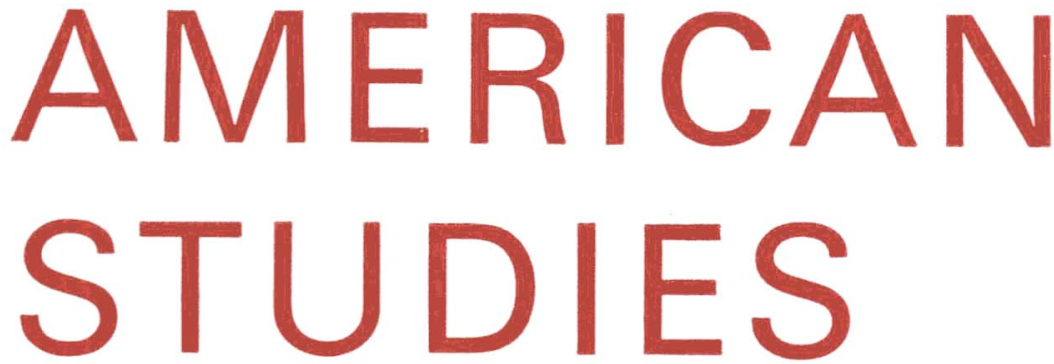

Cambridge University Press

for the British Association for American Studies 


\title{
AMERICAN STUDIES
}

\author{
EDITOR: Professor Dennis Welland, \\ University of Manchester \\ EDITORIAL BOARD: Professor MaLColm Bradbury, \\ University of East Anglia \\ Professor Marcus Cunliffe, \\ University of Sussex \\ Dr Charlotte Erickson, \\ London School of Economics \\ Dr Philip HafFenden, \\ University of Southampton \\ Professor MaLdWyn JONES, \\ University of Manchester \\ Professor D. G. MacRae, \\ London School of Economics \\ Professor H. G. Nicholas, \\ New College, Oxford \\ DR J. R. Pole, \\ Churchill College, Cambridge \\ Professor Henry Nash Smith, \\ University of California, Berkeley \\ Professor C. VANN WOODWARD, \\ Yale University
}

The Journal aims to promote the study of the history, institutions, literature and culture of the United States.

It publishes work by specialists of any nationality on American history, literature, politics, geography and related subjects. Articles which cross the conventional lines of those disciplines are welcome, as are comparative studies of American and other cultures. It also disser.inates information about work in progress and provides a platform for the exchange of scholarly information and opinion.

The editorial policy is not committed to any political viewpoint or ideology, but will not preclude responsible discussion of controversial topics.

Subscriptions. The Journal is published twice a year. The annual subscription is $£_{2} .00$ net U.K. (U.S.A. $\$ 6.50$ ); single parts are available at $£_{\mathrm{r}} \mathrm{r} .37$ net U.K. (U.S.A. $\$ 4.5 \circ$ ) each, plus postage. Orders should be sent to your usual bookseller or subscription agent, or direct to Cambridge University Press, Bentley House, 200 Euston Road, London NW 2 DB or, in U.S.A. and Canada, Cambridge University Press, 32 East $57^{\text {th }}$ Street, New York, N.Y. 10022. Claims for missing issues should be made not later than three months after publication.

Advertising. Enquiries about advertising in this journal should be sent to the publishers. 